\title{
Het implementeren van enkelzijdig beeldbellen
}

Vincent van Vugt, Serge Dijkgraaf, Ingrid Elfering

Begin 2020 werd de huisartsenzorg door de COVID-19pandemie sterk ontregeld. Vanwege het besmettingsrisico werden face-to-face consulten in de huisartsenpraktijk zoveel mogelijk beperkt. Om reguliere zorg te kunnen blijven leveren, zij het op afstand, hebben we daarom in onze huisartsenpraktijk met spoed beeldbellen ingevoerd. In dit artikel beschrijven we het implementatietraject: het protocol, de ervaringen van patiënten en huisartsen en onze aanbevelingen voor de toekomst.

Beeldbellen geldt al jaren als een belofte voor de huisartsenzorg, maar de technologie is in de praktijk nog nauwelijks ingezet. ${ }^{1}$ COVID-19 heeft dat radicaal veranderd. Een enquête van het Nivel liet eind april 2020 zien dat 693 (48\%) van de 1443 bevraagde huisartsenpraktijken met spoed beeldbellen had ingevoerd. ${ }^{2}$ Meer dan $20 \%$ van de huisartsenpraktijken gaf aan dat ze beeldbellen ook na de pandemie wilden blijven inzetten. Maar het beeldbellen mag dan explosief zijn toegenomen, wetenschappelijk onderzoek naar de implementatie ervan blijft schaars. We besloten die implementatie daarom in kaart te brengen voor ons eigen gezondheidscentrum en te onderzoeken of artsen en patiënten onze implementatie van (enkelzijdig) beeldbellen acceptabel vonden. ${ }^{3}$ Ons gezondheidscentrum Haveneiland is 1 van de 16 gezondheidscentra binnen de Stichting Amsterdamse Gezondheidscentra (SAG) en biedt zorg aan 9400 patiënten in Amsterdam IJburg. Ten opzichte van het landelijk gemiddelde bevat onze populatie relatief veel patiënten met een migratieachtergrond en weinig ouderen. In het centrum werken 6 vaste huisartsen, 1 huisarts-in-opleiding en 4 vaste praktijkassistenten.

Voordat we startten met beeldbellen hebben we geïnventariseerd hoe onze huisartsen en praktijkassistenten ertegenaan keken. Dat deden we in semigestructureerde interviews met 5 huisartsen en de coördinerend praktijkassistent, uitgevoerd en opgenomen door 1 auteur (VV). Vanwege tijdsdruk hebben we de interviews niet thematisch geanalyseerd, maar gebruikt om het implementatieprotocol vorm te geven en te bepalen bij welke patiënten beeldbellen kon worden ingezet. Hierna registreerden de artsen gedurende 9 weken elk beeldbelconsult dat ze voerden. In de laatste 4 weken nodigden we ook patiënten uit om hun mening te geven over hun beeldbelconsult.

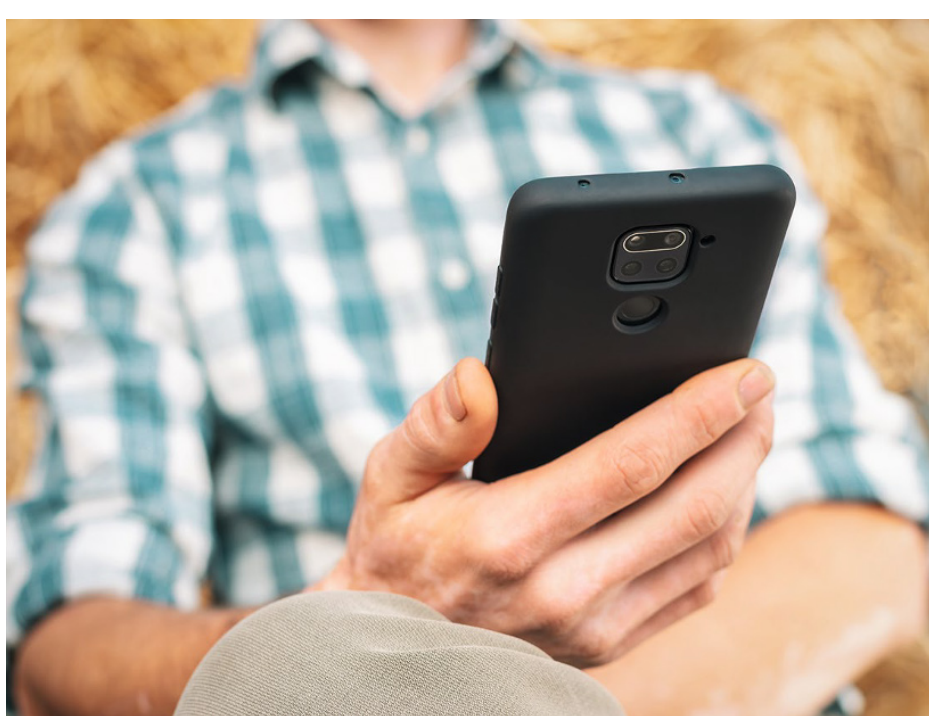

De meeste huisartsen en patiënten waren positief over de enkelzijdige beeldbelconsulten.

Foto: Shutterstock

\section{VOORBEREIDING: INTERVIEWS EN PROTOCOL}

In de voorbereidende interviews kwam een vaste lijst van punten aan de orde [bijlage 1]. Alle geïnterviewden waren enthousiast over de invoering van het beeldbellen en zagen het in principe als een nuttige innovatie. De voor- en nadelen die ze benoemden, zijn samengevat in [tabel 1]. We bespraken voor welk type klachten beeldbelconsulten geschikt zouden zijn en welke factoren het implementatieproces zouden kunnen verstoren.

Alle geïnterviewden gaven aan dat de beeldbelconsulten vooral eenvoudig op te zetten moeten zijn en technisch goed moeten werken. Aan de hand van deze informatie stelden we een eenvoudig inclusieprotocol op voor de praktijkassistenten [infographic]. In de agenda van de huisarts planden ze patiënten in die openstonden voor beeldbellen en aan de criteria voldeden als beeldbelconsult.

Voor de consulten zelf gebruikten we WeSeeDo, een applicatie waarmee parallel aan het telefoongesprek een eenzijdige, beveiligde videoverbinding kan worden opgezet. De huisarts nam telefonisch contact op met de patiënt en stuurde via sms een link naar diens mobiele telefoon. Door op deze link te klikken gaf de patiënt tijdelijk toegang tot de camera van zijn 


\section{Protocol implementatie beeldbellen}

De praktijkassistent bespreekt met patiënten die een consult met de arts nodig hebben de mogelijkheid tot beeldbellen. Hieronder staan de criteria voor de overweging om het wel of niet aan te bieden.

Let op! $\quad 00$

Wel aanbieden

- (Brand)wonden

- Beoordeling zwelling/kneuzing/breuk

- Huidziektes (uitslag, bultjes, vlekjes, ooglidproblemen, etc.)

- Klachten waarbij beoordeling van de algemene lichamelijke toestand kan helpen (bijvoorbeeld inschatten sufheid, kortademigheid of zien hoe iemand beweegt)

Beeldbellen aanbieden Twijfel: laagdrempelig overleg met arts
Als beeldbellen akkoord is, geeft de praktijkassistent de volgende uitleg aan de patiënt:

'Het beeldbellen met de huisarts werkt als volgt: De huisarts belt $u$ op en stuurt $u$ tijdens het gesprek een sms'je. Als u op dat sms'je klikt, krijgt de huisarts kortdurend toegang tot de camera van uw telefoon. Deze verbinding is veilig en er worden geen beelden opgeslagen.
Niet aanbieden

- Wanneer lichamelijk onderzoek nodig is

- Patiënten met veel emotie (boos, angstig, verdrietig)

- Patiënten bij wie je inschat dat ze hier niet mee overweg kunnen telefoon. Zo kon de huisarts wel de patiënt zien, maar de patiënt niet de huisarts. We vroegen de huisartsen om gedurende 9 weken na elk beeldbelconsult een korte (papieren) vragenlijst in te vullen [bijlage 2]; in de laatste 4 weken vroegen we ook patiënten om online een vragenlijst over hun beeldbelconsult in te vullen [bijlage 3 ].

\section{ERVARINGEN VAN HUISARTSEN}

In de 9 weken tussen 13 april en 12 juni 2020 registreerden we 85 enkelzijdige beeldbelconsulten [tabel 2]. De meeste beeldbelconsulten vonden plaats met relatief jonge patiënten en de ingangsklacht was bijna altijd (85\%) een dermatologisch probleem. [Tabel 3] laat zien dat de artsen in vrijwel alle consulten tevreden tot zeer tevreden waren over het contact met de patiënt en over de mate waarin zij de patiënt konden helpen. Over de technische aspecten waren de respondenten minder enthousiast: over 30\% van de beeldbelconsulten waren ze in dit opzicht ontevreden of neutraal. Desondanks hadden ze slechts in een klein aantal consulten nog behoefte aan een vervolgconsult face-to-face (13\%). Bij $80 \%$ van de consulten waren de artsen ook achteraf blij dat ze bij deze klacht voor een beeldbelconsult hadden gekozen.

\section{ERVARINGEN VAN PATIËNTEN}

In de 4 weken tussen 18 mei en 12 juni nodigden we ook de patiënten uit voor de (online) enquête. In deze periode 


\section{Tabel 1}

Voor- en nadelen van beeldbelconsulten volgens huisartsen $[n=5]$

\begin{tabular}{|c|c|c|}
\hline & Voordelen & Nadelen \\
\hline \multirow[t]{6}{*}{$\begin{array}{l}\text { Voor de } \\
\text { huisarts }\end{array}$} & $\begin{array}{l}\text { Beter contact houden met kwetsbare } \\
\text { patiënten tijdens de COVID-19- } \\
\text { pandemie }\end{array}$ & $\begin{array}{l}\text { Kan frustrerend zijn wanneer techno- } \\
\text { logie niet goed werkt }\end{array}$ \\
\hline & $\begin{array}{l}\text { Mogelijkheid tot flexibeler werken, } \\
\text { eventueel ook vanuit huis }\end{array}$ & Kost mogelijk meer tijd [in het begin] \\
\hline & $\begin{array}{l}\text { Biedt meer klinische informatie dan } \\
\text { telefonisch consult }\end{array}$ & $\begin{array}{l}\text { Mogelijk verkeerde beslissingen door } \\
\text { vertrouwen op beeldbelconsult }\end{array}$ \\
\hline & $\begin{array}{l}\text { Moderne, hightech uitstraling van de } \\
\text { praktijk }\end{array}$ & $\begin{array}{l}\text { Risico op verlies van autonomie door } \\
\text { andere organisatie van zorg }\end{array}$ \\
\hline & $\begin{array}{l}\text { Door triage met beeldbelconsulten } \\
\text { mogelijk minder visites nodig }\end{array}$ & \\
\hline & $\begin{array}{l}\text { Tijdsbesparing doordat beeldbelcon- } \\
\text { sulten meer gericht zijn op } 1 \text { klacht } \\
\text { en patiënt minder uitweidt }\end{array}$ & \\
\hline \multirow[t]{5}{*}{$\begin{array}{l}\text { Voor de } \\
\text { patiënt }\end{array}$} & $\begin{array}{l}\text { Geen risico op besmetting door arts } \\
\text { tijdens de COVID-19-pandemie }\end{array}$ & $\begin{array}{l}\text { Kan frustrerend zijn wanneer techno- } \\
\text { logie niet goed werkt }\end{array}$ \\
\hline & $\begin{array}{l}\text { Tijdsbesparing door verdwijnen } \\
\text { reistijd naar praktijk }\end{array}$ & $\begin{array}{l}\text { Problemen met privacy door datalek- } \\
\text { ken of toehoorders }\end{array}$ \\
\hline & $\begin{array}{l}\text { Minder verstoring van de dag [geen } \\
\text { vrij nemen van werk, geen kinderop- } \\
\text { vang regelen] }\end{array}$ & $\begin{array}{l}\text { Minder persoonlijk contact dan } \\
\text { face-to-face consult }\end{array}$ \\
\hline & $\begin{array}{l}\text { Niet meer 'eindeloos' wachten in } \\
\text { spreekkamer, hoeven alleen digitaal } \\
\text { beschikbaar te zijn }\end{array}$ & $\begin{array}{l}\text { Gevoel dat ze niet modern genoeg } \\
\text { zijn wanneer beeldbelconsult mislukt }\end{array}$ \\
\hline & $\begin{array}{l}\text { Gevoel dat ze in een moderne, high- } \\
\text { tech praktijk zitten }\end{array}$ & \\
\hline
\end{tabular}

Tabel 2

Patiëntkenmerken en ingangsklachten in 85 enkelzijdige beeldbelconsulten

\begin{tabular}{|c|c|c|}
\hline Patiëntkenmerken & $\begin{array}{l}\text { Enquête artsen } \\
{[n=85]}\end{array}$ & $\begin{array}{l}\text { Enquête patiënten } \\
{[n=12]^{*}}\end{array}$ \\
\hline \multicolumn{3}{|l|}{ Geboortejaar } \\
\hline 1921-1940 & $1[1]$ & $1[8]$ \\
\hline 1941-1960 & 7 [8] & $2[17]$ \\
\hline 1961-1980 & 23 [27] & 5 [42] \\
\hline 1981-2000 & 17 [२०] & 4 [33] \\
\hline २૦૦૦-२૦२૦ & $37[44]$ & $0[0]$ \\
\hline Vrouw & $48[56]$ & $7[58]$ \\
\hline \multicolumn{3}{|l|}{ Ingangsklachten } \\
\hline Dermatologie & \multicolumn{2}{|l|}{72 [85] } \\
\hline $\begin{array}{l}\text { uitslag, blaasjes, jeuk, bultjes, ontsteking, } \\
\text { insectenbeet }\end{array}$ & \multicolumn{2}{|l|}{66} \\
\hline verdenking maligne huidafwijking & \multicolumn{2}{|l|}{6} \\
\hline \multirow{3}{*}{$\begin{array}{l}\text { Oogheelkunde } \\
\text { ooglidprobleem } \\
\text { overige oogklachten }\end{array}$} & \multicolumn{2}{|l|}{$6[7]$} \\
\hline & \multicolumn{2}{|l|}{3} \\
\hline & \multicolumn{2}{|l|}{3} \\
\hline \multirow{3}{*}{$\begin{array}{l}\text { Chirurgie } \\
\text { [brand]wond } \\
\text { trauma bewegingsapparaat }\end{array}$} & \multicolumn{2}{|l|}{$5[6]$} \\
\hline & \multicolumn{2}{|l|}{4} \\
\hline & \multicolumn{2}{|l|}{1} \\
\hline Overig $^{+}$ & \multicolumn{2}{|l|}{$2[2]$} \\
\hline
\end{tabular}

Cijfers zijn n [\%].

* Consultduur en type klacht werden niet uitgevraagd in de patiëntenquête.

† Overige klachten waren 'geluidje bij navelbreuk' en 'pijn bij kaak/oor'.

\section{DE KERN}

- COVID-19 heeft de animo voor beeldbellen bij huisartsen sterk doen toenemen, maar wetenschappelijk onderzoek naar de implementatie ervan blijft schaars.

- Beeldbelconsulten moeten eenvoudig op te zetten zijn, technisch goed werken en een eenvoudig inclusieprotocol hebben.

- Bijna alle enkelzijdige beeldbelconsulten leidden bij patiënt en huisarts tot tevredenheid over het contact en over de mate waarin de patiënt werd geholpen.

- Beeldbelconsulten betroffen voornamelijk dermatologische klachten, terwijl het protocol ook ruimte bood aan andere klachten.

registreerden we 38 beeldbelconsulten en 12 patiënten (38\%) vulden het vragenformulier in. Hun oordeel was zeer positief. Alle 12 patiënten waren tevreden of zeer tevreden over het contact en over de mate waarin zij geholpen waren, 11 patiënten $(92 \%)$ waren tevreden of zeer tevreden over de technische aspecten van het consult. De meesten (83\%) waren, net als de huisartsen, achteraf blij met de keuze voor een beeldbelconsult (slechts 2 van de 12 patiënten hadden achteraf liever een face-to-face consult gehad), en $92 \%$ zou ook bij een nieuwe klacht openstaan voor een beeldbelconsult.

\section{INTERPRETATIE VAN DE RESULTATEN}

Dit was een kleinschalig en snel uitgevoerd implementatieproject in 1 Amsterdams gezondheidscentrum, dus bij de interpretatie van de resultaten is voorzichtigheid geboden. Het protocol is vooraf opgesteld aan de hand van gestructureerde interviews, maar dataverzameling en analyse voldoen niet aan de eisen van volwaardig kwalitatief onderzoek.

Tijdens het implementatieproject werden per dag gemiddeld 2 beeldbelconsulten gevoerd, wat slechts een fractie was van alle consulten in ons gezondheidscentrum. Dat lag voor een deel aan de COVID-19-pandemie, die de omstandigheden voor dit veranderproces extra uitdagend maakte. Het aantal door patiënten beoordeelde beeldbelconsulten was laag en het is mogelijk dat kritische patiënten de enquête niet hebben ingevuld.

\section{EIGEN ERVARINGEN}

Tijdens het implementatieproject benoemden de huisartsen in ons gezondheidscentrum veel voordelen van beeldbellen. Eenvoud en technische betrouwbaarheid beschouwden ze als de belangrijkste succesfactoren. We ontwikkelden een eenvoudig protocol, zodat enkelzijdige beeldbelconsulten veilig konden worden aangeboden aan een grote groep patiënten bij uiteenlopende indicaties. Uit onze 9 weken durende registratie bleek dat verreweg de meeste beeldbelconsulten (85\%) een dermatologische klacht betroffen. In bijna alle consulten was zowel de patiënt als de huisarts naderhand tevreden over het contact en 
Oordeel van huisartsen over aspecten van enkelzijdige beeldbelconsulten

\begin{tabular}{|c|c|c|c|c|c|}
\hline & Zeer ontevreden & Ontevreden & Neutraal & Tevreden & Zeer tevreden \\
\hline Manier van contact $[n=80]^{*}$ & 0 & २ [२] & $3[4]$ & $44[52]$ & $31[37]$ \\
\hline Vooruit geholpen door beeldbelconsult [ $\mathrm{n}=80]^{*}$ & 0 & $1[1]$ & $9[11]$ & $37[44]$ & 33 [39] \\
\hline Technische aspecten beeldbelconsult [ $\mathrm{n}=80]^{*}$ & 0 & $16[19]$ & $9[11]$ & $30[35]$ & 25 [29] \\
\hline \multirow[t]{2}{*}{ Na beeldbelconsult nog face-to-face consult nodig? $[n=82]^{\dagger}$} & nee & ja & & & \\
\hline & $71[84]$ & $11[13]$ & & & \\
\hline \multirow[t]{2}{*}{ Blij met keuze voor beeldbelconsult? $[n=81]^{\ddagger}$} & ja & nee[1] & nee[2] & nee[3] & \\
\hline & $68[80]$ & $9[11]$ & 2 [2] & २ [2] & \\
\hline
\end{tabular}

Cijfers zijn n [\%].

* Bij 5 beeldbelconsulten niet ingevuld.

† Bij 3 beeldbelconsulten niet ingevuld.

‡ Bij 4 beeldbelconsulten niet ingevuld. Nee [1] = face-to-face consult was beter geweest; nee [2] = telefonisch consult was beter geweest; nee [3] = e-consult met foto was beter geweest.

over de mate waarin de patiënt werd geholpen. De technische betrouwbaarheid verdient wel verbetering; in bijna 1 op de 3 consulten was de huisarts daarover niet tevreden.

Desalniettemin hebben we (enkelzijdig) beeldbellen gestructureerd kunnen invoeren en belangrijke lessen geleerd. Het verraste ons dat de beeldbelconsulten voornamelijk bij dermatologische klachten werden gevoerd, terwijl ons protocol ruimte gaf aan meer verschillende klachten. Een mogelijke verklaring is dat het protocol dermatologische klachten expliciet vermeldde. Ook kan hebben meegespeeld dat we alleen eenzijdig konden beeldbellen. Bij tweezijdig beeldbellen kun je als arts beter contact maken met de patiënt en zou ons protocol in theorie kunnen leiden tot ruimere inzet van beeldbellen bij meer indicaties.

\section{WAT IS ER BEKEND VANUIT DE LITERATUUR?}

In Britse kwalitatieve onderzoeken zijn ongeveer dezelfde voor- en nadelen van beeldbelconsulten genoemd als die onze huisartsen noemden en bleek ook de bereidheid van patiënten om te beeldbellen groot. ${ }^{4,5}$ Andere conclusies waren dat beeldbelconsulten qua inhoud, consultduur en kwaliteit gelijkwaardig zijn aan telefonische consulten, maar dat beide qua kwaliteit van communicatie onderdoen voor face-to-face consulten. ${ }^{6}$ Beeldbellen lijkt vooral geschikt bij jonge, technisch vaardige patiënten met enkelvoudige problemen. ${ }^{5,6}$ Volgens de meeste onderzoekers zullen beeldbelconsulten pas een vaste plaats krijgen in het aanbod van de huisarts wanneer de technologie betrouwbaarder wordt en naadloos is verweven in de werkprocessen. ${ }^{1,4-7}$ Integratie van beeldbellen in het huisartseninformatiesysteem is wat ons betreft dan ook een vereiste voor duurzame implementatie, zodat je met 1 klik in het dossier contact kunt leggen met de patiënt.

\section{CONCLUSIE}

Huisartsen zien veel voordelen van beeldbellen en zowel huis- artsen als patiënten waren in ons onderzoek positief over de enkelzijdige beeldbelconsulten, mits deze goed verliepen. We hebben in dit implementatieproject een protocol ontwikkeld voor enkelzijdig beeldbellen in de huisartsenpraktijk en we hopen dat andere praktijken deze informatie kunnen gebruiken om deze nieuwe vorm van zorg snel aan te bieden en te evalueren. Anno 2021 zouden huisarts en patiënt eenvoudig en betrouwbaar moeten kunnen beeldbellen. Als we dit in de praktijk weten te realiseren, verdient beeldbellen ook na de COVID-19-pandemie een vaste plek in ons arsenaal.

\section{DANKBETUIGING}

We willen graag alle huisartsen, praktijkassistenten en patiënten van SAG Gezondheidscentrum Haveneiland bedanken die hebben meegewerkt. Onze speciale dank gaat uit naar Esra Tekin, de praktijkassistent die samen met ons de implementatie heeft gecoördineerd.

\section{LITERATUUR}

1. Schers HJ, Buitenhuis E, Besemer Y. Videoconsultatie in de huisartsenpraktijk. Ned Tijdschr Geneeskd 2014;158:A8003.

2. Van Tuyl LH, Batenburg R, Keuper JJ, et al. Toename gebruik e-health in de huisartsenpraktijk tijdens de coronapandemie: organisatie van zorg op afstand in coronatijd. Utrecht: Nivel, 2020.

3. Proctor E, Silmere H, Raghavan R, et al. Outcomes for implementation research: conceptual distinctions, measurement challenges, and research agenda. Adm Policy Ment Health 2011;38:65-76.

4. Randhawa RS, Chandan JS, Thomas T, et al. An exploration of the attitudes and views of general practitioners on the use of video consultations in a primary healthcare setting: a qualitative pilot study. Prim Health Care Res Dev 2019;20:e5.

5. Donaghy E, Atherton H, Hammersley V, et al. Acceptability, benefits, and challenges of video consulting: a qualitative study in primary care. Br J Gen Pract 2019;69:e586-94.

6. Hammersley V, Donaghy E, Parker R, et al. Comparing the content and quality of video, telephone, and face-to-face consultations: a non-randomised, quasi-experimental, exploratory study in UK primary care. Br J Gen Pract 2019;69:e595-604. 
7. Thiyagarajan A, Grant C, Griffiths F, et al. Exploring patients' and clinicians' experiences of video consultations in primary care: a systematic scoping review. BJGP Open 2020;4.bjgpopen20X101020.
Van Vugt VA, Dijkgraaf SP, Elfering IM. Het implementeren van enkelzijdig beeldbellen. Huisarts Wet 2021;64:D0l:10.1007/s12445-0211079-1.

SAG Gezondheidscentrum Haveneiland, Amsterdam: dr. V.A. van Vugt, huisarts-in-opleiding en postdoctoraal onderzoeker [tevens Amsterdam UMC afdeling Huisartsgeneeskunde en Amsterdam Public Health onderzoeksinstituut], v.vanvugt@amsterdamumc.nl; S.P. Dijkgraaf, huisarts; I.M. Elfering, huisarts.

Mogelijke belangenverstrengeling: niets aangegeven. 


\section{Bijlage 1}

\section{Onderwerpen in de voorbereidende interviews met huisartsen}

- Hoe kijk jij tegen beeldbellen met patiënten aan?

- Heb je ooit eerder met beeldbellen gewerkt op een andere plek?

- Welke voordelen voor jezelf en de patiënten kun je bedenken bij beeldbellen?

- Welke nadelen voor jezelf en de patiënten kun je bedenken bij beeldbellen?

- Bij welke problematiek/pathologie denk je dat beeldbellen kan worden ingezet?

\section{Bijlage 2}

\section{Enquête voor de huisarts}

1. Initialen arts:

2. Datum consult:

3. Decennium waarin patiënt geboren is (omcirkel antwoord):

\begin{tabular}{|c|c|c|c|}
\hline $1940-1950$ & $1951-1960$ & $1961-1970$ & $1971-1980$ \\
\hline $1981-1990$ & $1991-2000$ & $2001-2010$ & $2011-2020$ \\
\hline
\end{tabular}

4. Geslacht patiënt: man vrouw

5. Beschrijving klacht:

6. Hoe lang duurde het videoconsult (start consult $\mathrm{t} / \mathrm{m}$ rapportage in HIS)? minuten

7. Was u tevreden over het contact met de patiënt in het videoconsult?

\begin{tabular}{|c|c|c|}
\hline zeer ontevreden & ontevreden & neutraal \\
\hline tevreden & zeer tevreden & \\
\hline
\end{tabular}

8. Was u tevreden over hoe $\mathrm{u}$ de patiënt vooruit heeft geholpen met het videoconsult?

\begin{tabular}{|c|c|c|}
\hline zeer ontevreden & ontevreden & neutraal \\
\hline tevreden & zeer tevreden & \\
\hline
\end{tabular}

- Bij welk type patiënt denk je dat beeldbellen geschikt of juist niet geschikt is?

- Wat zou bijdragen bij het invoeren van beeldbellen in je dagelijkse werk?

- Welke barrières zie je bij het invoeren van beeldbellen in je dagelijkse werk?

- Zie je ook een rol voor de assistentes bij beeldbellen? En zo ja, welke?
9. Was u tevreden over hoe het videoconsult technisch verliep?

\begin{tabular}{|c|c|c|}
\hline zeer ontevreden & ontevreden & neutraal \\
\hline tevreden & zeer tevreden & \\
\hline
\end{tabular}

10. Is er nog een live consult in de spreekkamer nodig na dit videoconsult?

ja, omdat

nee

11. Bent $\mathrm{u}$ achteraf tevreden met de keuze voor een videoconsult bij deze klacht?

ja

nee, een telefonisch consult zonder video was gelijkwaardig of prettiger geweest

nee, een live consult in de praktijk was prettiger geweest

12. Heeft u nog andere opmerkingen over dit videoconsult? 


\section{Bijlage 3}

\section{Enquête voor de patiënt}

1. Datum consult:

2. Decennium waarin patiënt geboren is (omcirkel antwoord):

\begin{tabular}{|c|c|c|c|}
\hline $1940-1950$ & $1951-1960$ & $1961-1970$ & $1971-1980$ \\
\hline $1981-1990$ & $1991-2000$ & $2001-2010$ & $2011-2020$ \\
\hline
\end{tabular}

3. Geslacht patiënt: man vrouw

4. Was u tevreden over het contact met de dokter in het videoconsult?

\begin{tabular}{|c|c|c|}
\hline zeer ontevreden & ontevreden & neutraal \\
\hline tevreden & zeer tevreden & \\
\hline
\end{tabular}

5. Was u tevreden over hoe $\mathrm{u}$ vooruit bent geholpen met het videoconsult?

\begin{tabular}{|c|c|c|}
\hline zeer ontevreden & ontevreden & neutraal \\
\hline tevreden & zeer tevreden & \\
\hline
\end{tabular}

6. Was u tevreden over hoe het videoconsult technisch verliep?

\begin{tabular}{|c|c|c|}
\hline zeer ontevreden & ontevreden & neutraal \\
\hline tevreden & zeer tevreden & \\
\hline
\end{tabular}

7. Bent $\mathrm{u}$ achteraf tevreden met de keuze voor een videoconsult bij deze klacht?

ja

nee, een telefonisch consult zonder video was prettiger geweest

nee, een consult in de praktijk bij de dokter was prettiger geweest

8. Zou u in de toekomst voor andere klachten eventueel ook een videoconsult willen?

ja

nee

9. Heeft u nog andere opmerkingen over dit videoconsult? 